\title{
BMC
}

Physiology

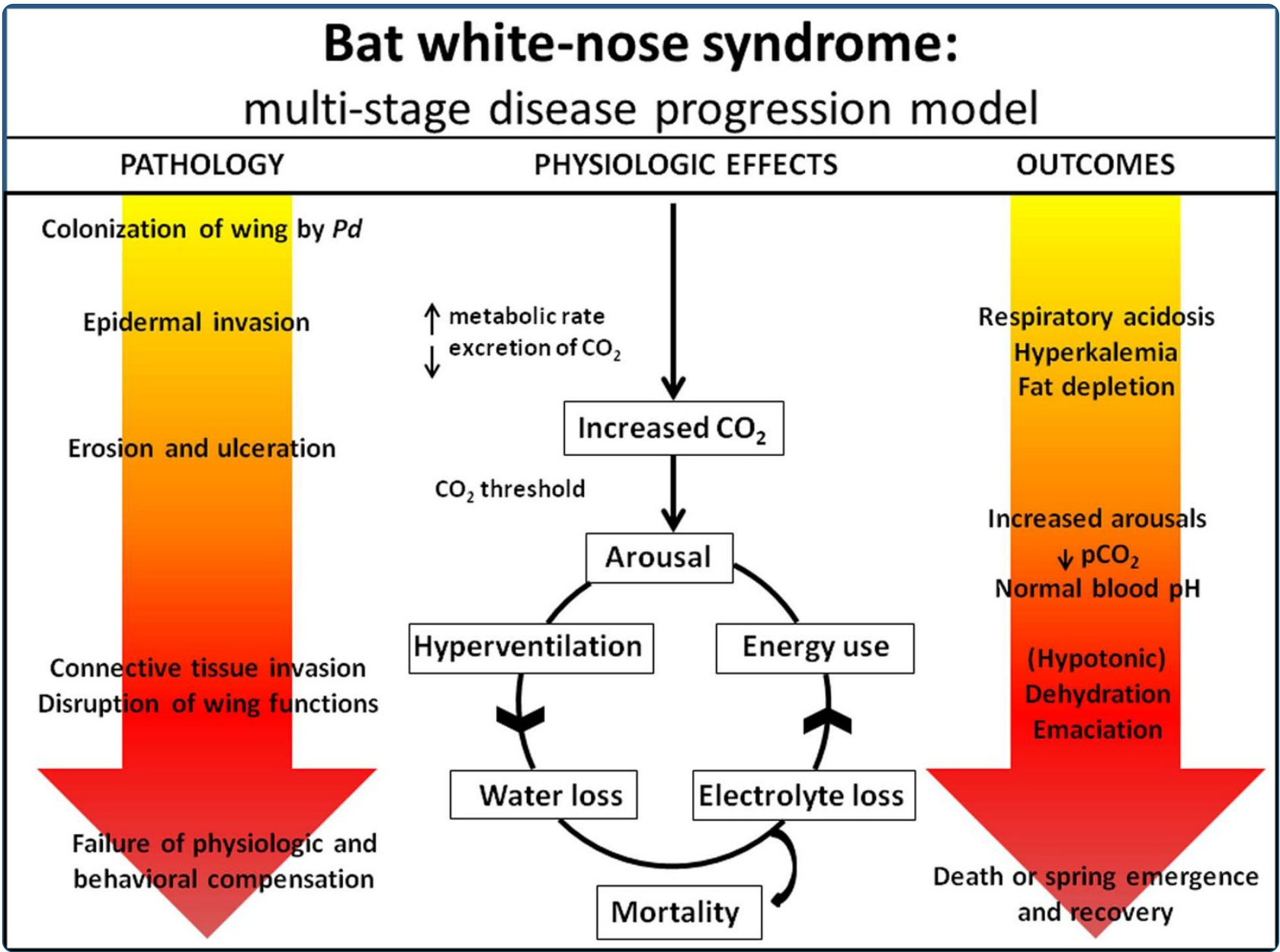

\section{White-nose syndrome initiates a cascade of physiologic disturbances in the hibernating bat host}

Verant et al. 


\title{
White-nose syndrome initiates a cascade of physiologic disturbances in the hibernating bat host
}

Michelle L Verant ${ }^{1}$, Carol U Meteyer ${ }^{2,5}$, John R Speakman ${ }^{3}$, Paul M Cryan ${ }^{4}$, Jeffrey M Lorch ${ }^{1}$ and David S Blehert ${ }^{2 *}$

\begin{abstract}
Background: The physiological effects of white-nose syndrome (WNS) in hibernating bats and ultimate causes of mortality from infection with Pseudogymnoascus (formerly Geomyces) destructans are not fully understood. Increased frequency of arousal from torpor described among hibernating bats with late-stage WNS is thought to accelerate depletion of fat reserves, but the physiological mechanisms that lead to these alterations in hibernation behavior have not been elucidated. We used the doubly labeled water (DLW) method and clinical chemistry to evaluate energy use, body composition changes, and blood chemistry perturbations in hibernating little brown bats (Myotis lucifugus) experimentally infected with $P$. destructans to better understand the physiological processes that underlie mortality from WNS.

Results: These data indicated that fat energy utilization, as demonstrated by changes in body composition, was two-fold higher for bats with WNS compared to negative controls. These differences were apparent in early stages of infection when torpor-arousal patterns were equivalent between infected and non-infected animals, suggesting that $P$. destructans has complex physiological impacts on its host prior to onset of clinical signs indicative of late-stage infections. Additionally, bats with mild to moderate skin lesions associated with early-stage WNS demonstrated a chronic respiratory acidosis characterized by significantly elevated dissolved carbon dioxide, acidemia, and elevated bicarbonate. Potassium concentrations were also significantly higher among infected bats, but sodium, chloride, and other hydration parameters were equivalent to controls.

Conclusions: Integrating these novel findings on the physiological changes that occur in early-stage WNS with those previously documented in late-stage infections, we propose a multi-stage disease progression model that mechanistically describes the pathologic and physiologic effects underlying mortality of WNS in hibernating bats. This model identifies testable hypotheses for better understanding this disease, knowledge that will be critical for defining effective disease mitigation strategies aimed at reducing morbidity and mortality that results from WNS.
\end{abstract}

Keywords: White-nose syndrome, Bats, Doubly labeled water

\section{Background}

Since emergence of white-nose syndrome (WNS) in 2007, bat populations of eastern North America have declined precipitously due to disease-related mortality [1-3]. The causative agent of WNS is the fungus Pseudogymnoascus (formerly Geomyces) destructans [4-6], which erodes unfurred skin comprising wing membranes, muzzles, and ears of hibernating bats, inducing

\footnotetext{
* Correspondence: dblehert@usgs.gov

${ }^{2}$ US Geological Survey National Wildlife Health Center, 6006 Schroeder Rd., Madison, Wisconsin, USA

Full list of author information is available at the end of the article
}

physiological perturbations, altered behavior, and death [7]. Although underlying causes for mortality from this invasive cutaneous mycosis remain unclear, proposed mechanisms include disruptions to vital homeostatic functions such as thermoregulation and water balance [8]. For example, water and electrolyte losses across the ulcerated wing epithelium have been proposed to cause hypotonic dehydration [9] and acid base disturbances [10]. Consequently, alterations in behavior have been observed in infected bats, including increased frequency of arousal from torpor during hibernation $[11,12]$ and unusual day flights during winter [3]. High metabolic 
demands of such activities [13-15] likely also contribute to mortality of bats prior to spring emergence by accelerating depletion of fat reserves. However, physiological data linking altered behavior to increased energy demands in bats with WNS are lacking.

The doubly labeled water (DLW) method is widely applicable to the study of energetics in relation to homeostasis, behavioral adaptations, and resource allocation in both animals and humans [16]. This method is based on dynamic flux of hydrogen and oxygen through the body and ability to measure these flux rates over a period of time using labeled isotopes, ${ }^{2} \mathrm{H}$ and ${ }^{18} \mathrm{O}$ [17]. Following administration of these exogenous isotopes, they equilibrate throughout the body water pool. The total body water volume (TBW) can then be estimated from the dilution spaces of the isotopes when introduced at known concentrations and serves as a valuable indicator of body composition (ratio of lean body mass to fat) [18]. Notably the DLW method has been used in temperate-zone insectivorous bats in the wild (e.g., Myotis lucifugus [19] and Eptesicus fuscus [20]), but there are no published reports of this method being used in bats hibernating over a protracted time period (i.e., months).

To evaluate proposed causes of mortality from WNS, we used the DLW method to quantify energy expenditure and changes in body composition of hibernating little brown bats ( $M$. lucifugus) experimentally infected with $P$. destructans to test the hypothesis that WNS increases metabolic demands during hibernation. We predicted that infected bats would exhibit greater changes in body composition, specifically decreased proportion of fat mass, over the course of the experiment compared to negative control bats as a result of higher daily energy expenditures and fat utilization. To further characterize previously reported physiologic outcomes associated with WNS, we analyzed blood chemistries of all bats at the end of the experiment to assess acid base balance, electrolytes, and hydration status.

\section{Results}

\section{Infection status and torpor patterns}

Of the 39 bats treated with conidia from P. destructans, 32 bats (14 male, 18 female) developed epidermal wing lesions characteristic of WNS by the end of the 98-d experiment. The majority of these bats $(n=30)$ had mild to moderate WNS (severity scores 1 or 2 with median score of 1), while the remaining two had moderate to severe WNS (severity scores 3 and 4). Sex had no effect on the probability that a bat developed WNS (Fishers Exact Test, $\mathrm{p}=0.4075)$. All infected bats, including animals that did not develop detectable WNS by histology $(\mathrm{n}=7)$, were PCR-positive for $P$. destructans; all bats in the control (non-infected) group were PCR-negative for the fungal pathogen. Four infected bats and five control bats died prior to the end of the experiment.

Average torpor bout duration for infected bats following DLW injection was 9.13 (2.31) d with average arousal duration of 54 (10) min. Average torpor bout duration for control bats following DLW injection was 8.52 (2.34) d with average arousal duration of 55 (11) min. Differences in torpor-arousal patterns of bats between treatment groups were not significant (torpor bout duration, $\mathrm{p}=0.5337$; arousal duration $\mathrm{p}=0.6508)$.

\section{Blood chemistry}

Blood chemistry parameters were analyzed for 27 infected bats (10 male, 17 female) and 11 control bats (6 male, 5 female) from which sufficient blood sample volumes were collected. One infected bat did not have skin lesions characteristic of WNS on histopathology, but there were no discernible differences across parameters when compared to infected bats with confirmed WNS. Additionally, we were unable to collect sufficient blood volume for analysis from the two bats with most advanced pathology (WNS severity scores 3 and 4). Thus, blood chemistry values presented herein for infected bats represent bats with mild WNS pathology (median severity score of 1 ).

Infected bats had significantly lower blood $\mathrm{pH}$ than controls (Table 1, Figure 1a). This acidemia was associated with a significant elevation of $\mathrm{pCO}_{2}$ in infected bats compared to controls (Table 1, Figure 1a), indicating that bats had respiratory acidosis. Bicarbonate levels of infected bats were also significantly higher than those of non-infected controls (Table 1, Figure 1a), evident of a compensatory renal response to a chronic acidosis. The accumulation of bicarbonate in blood of infected bats was also reflected in an elevated base excess compared to controls (Table 1). There were no differences in sodium or chloride concentrations between treatment groups, but potassium concentration was significantly higher in the infected bats than it was in the controls (Table 1, Figure 1b). Glucose concentrations were lower in infected bats but not significantly (Table 1), and anion gap values were not different from controls nor elevated as would be expected if acidemia resulted from metabolic lactic or keto-acidosis. Other measures of hydration status (hematocrit, blood urea nitrogen, and total protein) were equivalent between treatment groups (Table 1, Figure 1c). Overall, there were no effects of sex (two-way MANOVA, Pillais Trace $=0.48, \mathrm{~F}(9,14)=1.46$, $\mathrm{p}=0.25$ ) or the interaction of sex and treatment (two-way MANOVA, Pillais Trace $=0.53, \mathrm{~F}(9,14)=1.79, \mathrm{p}=0.16$ ) on measured blood parameters. See Additional file 1 for a complete table of blood chemistry parameter estimations compared to available reference values. 
Table 1 Blood chemistry comparisons

\begin{tabular}{lllll}
\hline Parameter & $\boldsymbol{k}$ & $\mathbf{d f}$ & Unadjusted $\mathbf{p}$-value $\mathbf{a}=\mathbf{0 . 0 5}$ & Holm-Bonferroni corrected $\mathbf{p}$-value $(\mathbf{a} / \boldsymbol{k})$ \\
\hline $\mathrm{pCO}_{2}$ & 12 & 38 & $<0.0001^{*}$ & .0042 \\
$\mathrm{~K}$ & 11 & 35 & $<0.0001^{*}$ & .0045 \\
$\mathrm{pH}$ & 10 & 38 & $<0.0001^{*}$ & .0050 \\
$\mathrm{HCO}_{3}^{-}$ & 9 & 36 & $<0.0001^{*}$ & .0056 \\
$\mathrm{BE}$ & 8 & 37 & $<0.0001^{*}$ & .0063 \\
$\mathrm{Glucose}$ & 7 & 26 & .0144 & .0071 \\
$\mathrm{AG}$ & 6 & 26 & .0483 & .0083 \\
$\mathrm{Cl}$ & 5 & 22 & .0646 & .01 \\
$\mathrm{BUN}$ & 4 & 36 & .2093 & .0125 \\
$\mathrm{TP}^{-}$ & 3 & 36 & .6085 & .0167 \\
$\mathrm{Na}^{+}$ & 2 & 36 & .7079 & .025 \\
$\mathrm{HCt}$ & 1 & 23 & .8396 & .05 \\
\hline
\end{tabular}

Abbreviations: $p \mathrm{CO}_{2}$ dissolved carbon dioxide, $\mathrm{K}$ potassium, $\mathrm{HCO}_{3}^{-}$bicarbonate, $B E$ base excess, $A G$ anion gap, $\mathrm{Cl}^{-}$chloride, $B U N$ blood urea nitrogen, $T P$ total protein, $\mathrm{Na}^{+}$sodium, $\mathrm{Hct}$ hematocrit.

Results of $t$-tests used to compare mean blood chemistry parameters for little brown bats (Myotis lucifugus) either experimentally infected with Pseudogymnoascus destructans or negative (non-infected) controls. Significant differences between treatment groups $\left(^{*}\right.$ ) were determined by $p$-values $<$ Holm-Bonferroni $p$-values corrected by the index of comparison $(k)$.

\section{Measurements of daily energy expenditure and total body water}

Upon collection of final blood samples, $67 \mathrm{~d}$ after injection with DLW, labeled isotope concentrations had decreased to levels statistically indistinguishable from background levels. Consequently, isotope turnover rates and daily energy expenditure (DEE) could not be determined for bats euthanized at the end of the experiment. However, one bat in the control group that died $35 \mathrm{~d}$ after initial injection of DLW had detectable isotope concentrations at time of death. For this bat, $\mathrm{k}_{\mathrm{d}}$ and $\mathrm{k}_{\mathrm{o}}$ were 0.004 , calculated respiratory $\mathrm{CO}_{2}$ production $\left(r \mathrm{CO}_{2}\right)$ was $0.01 \mathrm{ml} / \mathrm{min}$, and resultant DEE was $0.44 \mathrm{~kJ} /$ day.

Measurements of total body water (TBW) were available for 26 bats (19 infected, 7 controls) following initial injection of DLW and for 24 bats (17 infected, 7 controls) after final injection (Table 2). The reduction in sample size is attributed to mortality of bats during the experiment or inability to collect a sufficient amount of blood for isotope analyses. At the time of initial DLW injection, mean TBW as percent of body mass (TBW \% BM) was significantly lower for infected bats than controls (Tables 2 and 3), but mean body mass was not different between groups $(t=-0.5925, \mathrm{df}=30, \mathrm{p}=0.558)$. After $67 \mathrm{~d}$ hibernation, changes in TBW and body mass were compared for infected and control bats for which paired measurements were available. Body mass decreased significantly in both treatment groups (infected: $\mathrm{t}=11.32$, $\mathrm{df}=13, \mathrm{p}<0.0001$; control: $\mathrm{t}=14.24, \mathrm{df}=3, \mathrm{p}=0.0008)$, but the loss in body mass was equal between groups. Changes in TBW \% BM were marginally significant between infected and control bats, but not when corrected for multiple comparisons (Tables 2 and 3). Within groups, infected bats, which all developed mild WNS ( $\mathrm{n}=14$; median WNS severity score 1 , range 12 ) exhibited a significant increase in TBW \% BM (Tables 2 and 3); increase in TBW \% BM among control bats $(n=4)$ was not significant (Tables 2 and 3 ).

As trends in TBW, namely TBW \% BM, reflect changes in body composition, net fat energy utilization was calculated from the change in TBW (in g) and body mass measurements for all bats with paired data assuming constant $73 \%$ water content of lean mass (see Additional file 2). Based upon these calculations, mean total fat energy utilization for the $67 \mathrm{~d}$ after which bats were administered DLW was significantly higher for bats with WNS compared to negative controls (Tables 2 and 3).

\section{Discussion}

Results of this study support the hypothesis that infection with $P$. destructans and subsequent development of WNS increases energy (fat) use in hibernating bats and provide key information for understanding the progression of physiologic disturbances that ultimately lead to mortality from this disease. Specifically, isotope-based estimates of changes in body composition provided evidence that hibernating little brown bats with WNS utilized twice as much energy as non-infected control bats housed under equivalent experimental conditions. However, the greater energy use by infected bats was not associated with an increased rate or duration of arousals from torpor. This implies that bats, even with mild WNS lesions, have an elevated metabolism prior to the onset of altered arousal patterns characteristic of late-stage infections [12]. Additionally, bats with early-stage WNS developed severe, chronic respiratory acidosis and hyperkalemia 
Figure 1 Blood chemistry parameters. Box-and-whisker plots of blood chemistry values for hibernating little brown bats (Myotis lucifugus) experimentally infected with Pseudogymnoascus destructans and negative (non-infected) controls. Parameters for acid-base balance (a), electrolytes (b) and hydration status (c) are shown. The median (bold line), upper and lower quartiles (box), and maximum and minimum values (whiskers) are shown. Potential outliers (points) shown were not confirmed by Bonferonni outlier tests. Significant differences $\left({ }^{*}\right)$ were determined at $a=0.05$ corrected for multiple comparisons by the Holm-Bonferonni method.

(high potassium concentrations in the blood). Integrating these results with those reported by others [7,9-12,21], we propose a mechanistic multi-stage disease progression model for WNS that encompasses our current knowledge of disease pathology and physiologic sequelae, including death, that result following infection by $P$. destructans (Figure 2).

As shown in this study, early stages of WNS involving fungal colonization of the wing membrane with progression to erosion and ulceration of the epidermis, are characterized by increased $\mathrm{CO}_{2}$ levels in blood, resultant acidemia, and hyperkalemia. The accumulation of $\mathrm{CO}_{2}$ may stem from either increased $\mathrm{CO}_{2}$ production from an elevated metabolic rate associated with infection, decreased $\mathrm{CO}_{2}$ expiration, possibly due to inhibition of diffusion across the damaged wing epithelium [7], and/or a compensatory response by the host to attempt to further lower torpor metabolic rates (and conserve fat reserves) by inducing a hypercapnic (high $\mathrm{pCO}_{2}$ ) acidosis [15,22-24]. This acidosis may then contribute to the observed hyperkalemia by an acidosis-induced extracellular shift of potassium. Intracellular potassium ions may also leak into the blood through damaged and necrotic cell membranes caused by hyphal invasion of the

Table 2 Body composition measurements
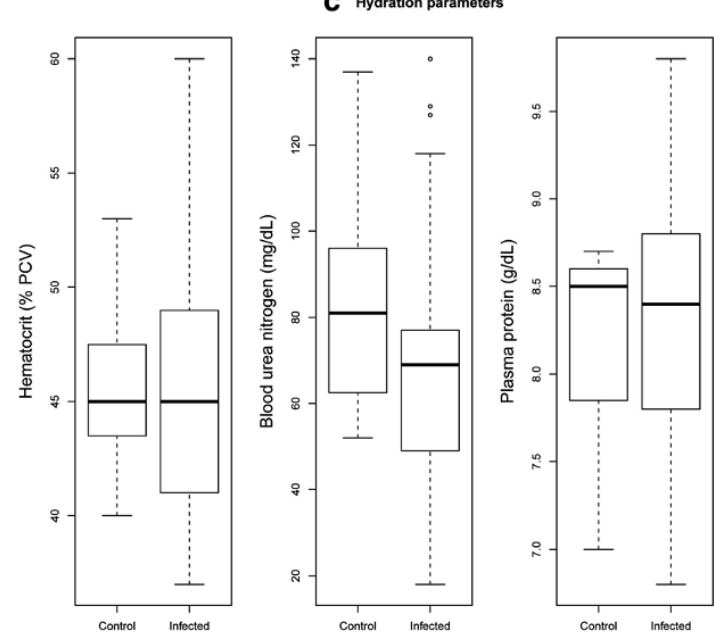

\begin{tabular}{lll}
\hline $\begin{array}{l}\text { Parameter } \\
\text { All data }\end{array}$ & $\begin{array}{l}\boldsymbol{P d} \text { infected bats } \\
\boldsymbol{n}=\mathbf{2 2}\end{array}$ & $\begin{array}{l}\text { Control bats } \\
\boldsymbol{n}=\mathbf{1 0}\end{array}$ \\
\hline Initial TBW \% BM & $53.4(4.3)$ & $58.8(2.4)$ \\
Final TBW \% BM & $60.5(3.9)$ & $61.0(4.6)$ \\
Initial BM (g) & $7.64(0.75)$ & $7.48(0.58)$ \\
Final BM (g) & $6.60(0.68)$ & $6.41(0.57)$ \\
Paired data & $n=14$ & $n=4$ \\
Change in TBW \% BM & $+9.1(3.5)$ & $+4.0(3.9)$ \\
Fat energy use (kJ) & $43.9(13.6)$ & $20.5(14.7)$ \\
\hline
\end{tabular}

Values of body mass (BM) and total body water as percentage of body mass (TBW \% BM) were used to estimate net fat energy use over $67 \mathrm{~d}$ for individual little brown bats (Myotis lucifugus) experimentally infected with

Pseudogymnoascus destructans and negative control (non-infected) bats. Values in the table are mean (SD) and $n=$ sample size. Initial TBW \% BM was significantly different between treatment groups. Over the course of the experiment, infected bats demonstrated a significant increase in TBW \% BM and used significantly more fat energy than non-infected bats. Body mass decreased significantly over the experiment in infected and control bats but there was no difference between groups. 
Table 3 Doubly labeled water comparisons

\begin{tabular}{lllll}
\hline Measurement & $\boldsymbol{k}$ & $\mathbf{d f}$ & Unadjusted $\mathbf{p}$-value $\mathbf{a}=\mathbf{0 . 0 5}$ & Holm-Bonferroni corrected $\mathbf{p}$-value $(\mathbf{a} / \mathbf{k})$ \\
\hline Fat energy use (I) & 8 & 13 & $<0.0001^{*}$ & 0.0063 \\
Change in TBW \% BM (I) & 7 & 13 & $<0.0001^{*}$ & 0.0071 \\
Initial TBW \% BM (I vS C) & 6 & 25 & $0.0041^{*}$ & 0.0083 \\
Fat energy use (I vs C) & 5 & 16 & $0.0088^{*}$ & 0.01 \\
Change in TBW \% BM (I vs C) & 4 & 16 & 0.0243 & 0.0125 \\
Fat energy use (C) & 3 & 3 & 0.0687 & 0.0167 \\
Change in TBW \% BM (C) & 2 & 3 & 0.1353 & 0.025 \\
Final TBW \% BM (I vs C) & 1 & 22 & 0.7841 & 0.05
\end{tabular}

Results of $t$-tests used to compare doubly labeled water measurements for little brown bats (Myotis lucifugus) either experimentally infected with Pseudogymnoascus destructans (I) or non-infected controls (C). Total body water is represented as percentage of body mass (TBW \% BM). Significant differences between treatment groups $\left({ }^{*}\right)$ were determined by $p$-values $<$ Holm-Bonferroni $p$-values corrected by the index of comparison $(k)$.

epidermis. Overall, these physiologic effects result in a chronic respiratory acidosis, hyperkalemia, and reduction of fat reserves among bats during early stages of WNS.

Consistent with results observed in bats at later and more severe stages of WNS $[9,10]$, we propose that once $\mathrm{pCO}_{2}$ elevates beyond a tolerance threshold, chemoreceptors stimulate hyperventilation, and resulting increased arousals from torpor serve to remove excess $\mathrm{CO}_{2}$, returning blood $\mathrm{pH}$ to normal [22,25-28]. The high energy demand of these arousals then likely further contributes to accelerated depletion of fat reserves. Additionally, increased ventilatory rates and greater vapor pressure difference with increased body temperatures during arousals would contribute to greater evaporative water loss [29] and dehydration. Together, these outcomes are consistent with data previously published for little brown bats with

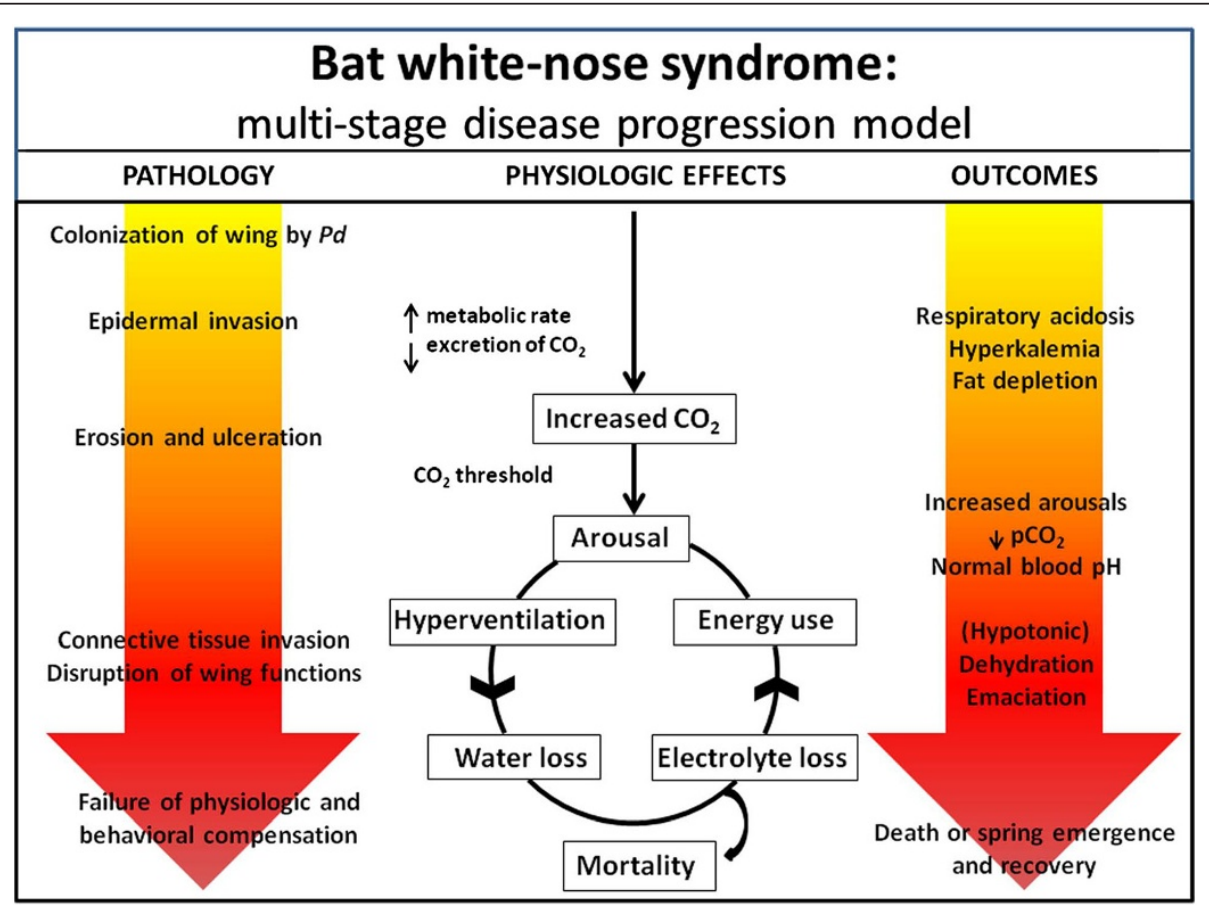

Figure 2 Disease progression model for bat white-nose syndrome (WNS). We propose a mechanistic multi-stage disease model for WNS in a hibernating bat that encompasses current knowledge on the progression of fungal-induced wing pathology and physiologic sequelae leading to mortality from disease. Initial colonization and invasion of the wing epidermis by Pseudogymnoascus destructans $(P d)$ results in increased energy expenditure, chronic respiratory acidosis (elevated blood $\mathrm{pCO}_{2}$ and bicarbonate), and hyperkalemia (elevated blood potassium). Erosion and ulceration of the epidermis stimulate increased frequencies of arousal from torpor, which remove excess $\mathrm{CO}_{2}$ and normalize blood pH, but contribute to dehydration and depletion of fat reserves. As wing pathology becomes more extensive and severe, these effects are exacerbated by water and electrolyte loss across the epidermis (hypotonic dehydration), which stimulate more frequent arousals and create a positive feedback loop that ultimately leads to mortality when energy reserves and compensatory mechanisms become exhausted. 
more severe WNS pathology that exhibited increased frequency of arousal from torpor, decreased $\mathrm{pCO}_{2}$, normal blood $\mathrm{pH}$, and dehydration [10].

As WNS progresses towards more extensive and severe wing lesions, dehydration may be further exacerbated by water and electrolyte loss across the damaged epidermis of the wing $[9,30]$, further stimulating arousal from hibernation to drink [29,31,32]. Positive feedback loops are then established that link worsening disease-associated wing pathology to further increases in arousal frequency, water loss, and energy use resulting in additional observed acute physiologic changes, including hypocapnia, hypoglycemia, hyponatremia, hypochloremia, and emaciation [9-11]. Once compensatory mechanisms such as cellular buffering, respiratory and metabolic regulation, and/or behavioral adaptations are exhausted, this suite of disturbances ultimately leads to mortality unless the bat has sufficient energy reserves to persist until spring emergence and clear the infection following a return to a metabolically active state [33].

Although normal reference ranges for blood chemistry values in microchiropteran species are generally lacking [34], deviations of measured parameters in infected bats from the negative controls in this study, together with published information for apparently healthy hibernating little brown bats [10,34-39], suggest pathologic and potentially life-threatening physiological disturbances associated with early-stage WNS infections [see Additional file 1]. Bats with WNS in this study had almost $40 \%$ higher mean $\mathrm{pCO}_{2}$ than negative control bats $(99.4$ and $37.1 \mathrm{mmHg}$ respectively), and $\mathrm{pCO}_{2}$ values above $90 \mathrm{mmHg}$ are generally considered to be lethal in other non-hibernating animals and humans. Elevated $\mathrm{pCO}_{2}$ levels and associated acidemia are known to interfere with enzymatic functions, reduce metabolic activity, and cause central depression of respiration; in severe cases, such elevated levels can lead to coma and death.

Direct calculations of energy expenditure could not be determined for most bats in this study because final isotope concentrations were indistinguishable from background levels. However, the increase in TBW as a percent of body mass observed in infected bats indicated that bats with WNS had higher proportions of lean tissue mass to fat tissue mass at the end of the study. This finding implies that bats with WNS used significantly more fat energy reserves compared to negative controls despite hibernating under equivalent conditions. From the estimated changes in fat content over the 67-d measurement period, infected bats utilized $0.65 \mathrm{~kJ} / \mathrm{d}$, while control bats utilized $0.31 \mathrm{~kJ} / \mathrm{d}$. These results indicate that bats with WNS expended approximately twice as much energy during hibernation as non-infected control bats. Some caution must be taken in interpreting these results due to the small number of control bats for which paired TBW measurements were available to calculate estimates of fat use. However, the range of expected daily energy use of 0.27 to $0.51 \mathrm{~kJ} / \mathrm{d}$ predicted for healthy hibernating M. lucifugus at the mean temperature of our study [40] is consistent with the daily rates of energy use observed in control bats in this experiment, and lower than rates observed in infected bats. There were no differences in torpor-arousal patterns between treatment groups in this study suggesting that WNS causes an increase in metabolism that is not directly associated with arousal from torpor and occurs at early stages in disease progression. Additionally, there were no differences between infected and control bats in $\mathrm{T}_{\text {skin }}$ maintained during torpor or arousal bouts. Alternatively, metabolic costs associated with infection and development of wing pathology may be linked to increased costs of thermoregulation caused by inhibition of peripheral vasoconstriction during torpor and arousal [25], catabolism of fat to generate metabolic water in response to increased water loss, or additional energetic costs associated with the host-pathogen interaction.

Rising concentrations of $\mathrm{pCO}_{2}$ in a mammal would normally stimulate increased respiration to release excess $\mathrm{CO}_{2}$. However, the unique physiology of mammalian hibernators allows for active suppression of respiration during torpor, and under these conditions, blood $\mathrm{pCO}_{2}$ increases to levels higher than those observed in metabolically active mammals $[22,28,41,42]$. This elevation of $\mathrm{pCO}_{2}$ is thought to be an integral part of hibernation physiology as induction of an acidotic state serves to reduce metabolic rate and thermogenesis [25,43,44]. Additionally, the resultant high $\mathrm{pCO}_{2}$ gradient improves ventilation efficiency, thereby minimizing energy costs of respiration during torpor [23]. Despite this tolerance for a respiratory acidosis [45], a hibernating mammal must still be able to regulate $\mathrm{pCO}_{2}$ for proper physiologic function. If $\mathrm{CO}_{2}$ elimination routes, such as passive diffusion of $\mathrm{CO}_{2}$ across the wing epithelium $[46,47]$ are compromised by disease, as hypothesized for bats with WNS [7], persistently rising blood $\mathrm{pCO}_{2}$ levels would cause the severe chronic respiratory acidosis we have observed. Thus, underlying causes for the high $\mathrm{pCO}_{2}$ levels in bats with WNS are likely a combination of the uniquely adapted physiology of a hibernating mammal compounded by pathologically induced insult(s) to these physiological mechanisms.

Bat WNS presents a new paradigm for the study of infectious disease. Never before has a fungal skin pathogen been known to specifically infect a hibernating mammal, causing severe physiologic disturbances and mortality. Although substantial efforts have been devoted to understanding chytridiomycosis, a lethal fungal skin disease of amphibians, prior to WNS there had been no indepth study of disease processes in a metabolically repressed animal caused by a psychrophilic and metabolically active pathogen. The poorly characterized capacity of bats 
to compensate for and respond to infection during hibernation demonstrates the difficulty of understanding how host-pathogen interactions influence disease manifestation and mortality.

\section{Conclusions}

This study demonstrated that infection with $P$. destructans and subsequent development of WNS increased energy (fat) use in hibernating bats prior to the onset of altered arousal patterns associated with later stages of WNS. Severe, chronic respiratory acidosis and hyperkalemia were also apparent in bats that developed mild WNS. With these results, we present a multi-stage disease progression model for WNS as a framework for understanding the pathogenesis and underlying causes of mortality due to WNS (Figure 2). This model integrates a range of published work [7,9-12,21] with data from this study into the first attempt to mechanistically define a comprehensive conceptual model of what may occur during development of WNS in a hibernating bat from initial colonization of wing skin by $P$. destructans until the death of the animal. This model identifies key testable hypotheses necessary to develop a comprehensive understanding of the physiologic effects of WNS on hibernating bats. Ultimately, this knowledge will be critical for guiding effective and properly timed management actions to moderate physiologic effects of WNS and minimize morbidity and mortality from this devastating disease.

\section{Methods}

Bats

This study was conducted in accordance with experimental protocol \#110921 approved by the Institutional Animal Care and Use Committee of the USGS National Wildlife Health Center (NWHC). Sixty (30 male and 30 female) little brown bats (Myotis lucifugus) were collected from a hibernaculum in Wisconsin on December 21, 2012 and transported to NWHC. Bats were held individually within tube socks maintained in coolers at approximately $7 \mathrm{C}$ during transport. Body mass and right forearm length were recorded for each bat, and both wings of each bat were evaluated for pre-existing injuries. All animals were confirmed negative for $P$. destructans by polymerase chain reaction (PCR) [48] analysis of wing-skin swab samples (PurFlock nylon-flocked swabs, Puritan, Guilford, ME) collected from each bat. An archival temperature logger (iBBat, Alpha Mach) was affixed between the scapulae of each bat using a latex-based adhesive (Ostobond, M.O.C., Vaudreuil, Quebec, Canada) after trimming a $1 \mathrm{~cm} 1 \mathrm{~cm}$ patch of fur to within $1 \mathrm{~mm}$ of the skin surface. Loggers were programmed to record skin temperature $\left(\mathrm{T}_{\text {skin }}\right)$ every 15 minutes starting at the time of DLW injection until the end of the experiment. Torpor-arousal patterns were assessed using $\mathrm{T}_{\text {skin }}$ data downloaded from
iBBat temperature loggers following termination of the experiment. Arousal thresholds were defined as $10 \%$ of maximum $\mathrm{T}_{\text {skin }}$ for each individual [11].

Bats were sorted by sex and randomly assigned to infected ( $\mathrm{n}=39 ; 19$ males, 20 females) and control $(\mathrm{n}=21$; 11 males, 10 females) groups. Conidia of $P$. destructans (5 $10^{5}$ in $20 \mu \mathrm{l}$ of PBS with $0.5 \%$ Tween-20) were applied to the skin of the dorsal surface of both wings of each bat in the infected group as previously described [49]. PBS Tween-20 lacking conidia was similarly applied to the wings of control (non-infected) bats. Each group was placed into a mesh enclosure $\left(\begin{array}{llllll}22 & \mathrm{H} & 14 & \mathrm{~W} & 14 & \mathrm{D}\end{array}\right.$ Apogee Reptaria, Reptiledirect.com) within separate environmental incubators (Percival Scientific, Perry, IA) and maintained at $7.5 \mathrm{C}$ and $90 \% \mathrm{RH}$ for 98 days. Bats were monitored every other day for the duration of the experiment and any dead animals removed.

At the end of the experiment, all remaining bats were euthanized. Polymerase chain reaction (PCR) analyses of wing skin were performed as previously described [48] to confirm the presence of $P$. destructans. Additionally, the entire membrane of one wing was examined by histology to identify lesions diagnostic for WNS [21] and to assign severity scores [from 0 (no lesions) to 4 (severe, extensive lesions)] based on extent of fungal infection [11].

\section{Doubly labeled water}

The DLW method used a two-sample approach by measuring isotopic concentrations at equilibrium ( $1 \mathrm{~h}$ following DLW injection) and once more at the end of the experiment [17]. The duration of the elimination period was determined from estimates of isotope washout rates modeled using parameters of energy expenditure for hibernating little brown bats [40], assuming torpor bouts of 8 to $16 \mathrm{~d}$ interspersed by 0.5 to $1.5 \mathrm{~h}$ arousals, as recorded for little brown bats with and without WNS in previous experiments [12]. One additional arousal and a 3-h euthermic period were included in the model to account for initial DLW injection and blood collection at the end of the experiment. Based upon an energy expenditure budget of approximately $60 \mathrm{~kJ}$, isotope washout was predicted to occur 89 to $171 \mathrm{~d}$ post-administration of DLW. To increase the likelihood that labeled isotope concentrations would remain measurable over a duration of time sufficient for development of experimentally induced WNS (90 to $120 \mathrm{~d}$; $[12,49])$, we administered the first dose of DLW 28 $\mathrm{d}$ after treatment of bats with fungal conidia.

For administration of DLW, bats were removed from incubators and aroused at room temperature for 20 to $30 \mathrm{~min}$. Once fully aroused, both infected $(\mathrm{n}=34)$ and negative control $(\mathrm{n}=16)$ bats were injected intraperitoneally with approximately $70 \mu \mathrm{l}$ of a mixture of enriched ${ }^{18} \mathrm{O}$ (approximately 19 atom \%) and ${ }^{2} \mathrm{H}$ (approximately 11 atom \%). Dose enrichments were quantified using a 
standard dilution experiment [50]. Bats were then held at room temperature for approximately $1 \mathrm{~h}$ to allow for isotopic equilibration [20]. Following $1 \mathrm{~h}$ at euthermic temperatures, 50 to $75 \mu \mathrm{l}$ of blood was collected from the ventral aspect of the uropatagial vein of each bat [51] into two heparinized $100 \mu \mathrm{l}$ capillary tubes for determination of initial isotope concentrations and TBW. Ends of the capillary tubes were immediately flame-sealed, dipped in sealing wax, and stored at $4 \mathrm{C}$ until analysis. Bats were then returned to incubators and left undisturbed for the duration of the experiment. Additionally, five bats from each treatment group were used to measure background isotope levels [52]; these bats were treated identically as those described above, but they did not receive injections of DLW.

At 95 days post-treatment with conidia $(67 \mathrm{~d}$ after injection of DLW) bats were removed from hibernation chambers, aroused to euthermic body temperatures, and blood was collected (as above) to determine final isotope concentrations. Blood from bats that did not receive initial DLW injections was also sampled at this time to obtain a concurrent measure of background isotope levels. Since TBW content of each bat was assumed to have changed since sampling at the beginning of the experiment, a dose of the DLW solution used previously was administered to each bat, for which a non-terminal blood sample was collected, to determine TBW at the end of the experiment for infected $(n=22)$ and control $(\mathrm{n}=12)$ bats. Following the injection with DLW, bats were held at room temp for $1 \mathrm{~h}$ for isotopic equilibration, after which time they were anesthetized with $5 \%$ isoflurane and decapitated. Whole blood was collected into heparinized capillary tubes, and 50 to $75 \mu \mathrm{l}$ of blood was immediately sealed in capillary tubes (as described above) for isotope analysis. Rectal temperature was recorded at the time of euthanasia using a miniature probe and digital thermometer (Models RET-4 \& BAT7001H, Physitemp Instruments, Inc., Clifton, NJ).

\section{Blood chemistry}

Following euthanasia, blood chemistry parameters were analyzed for each bat as previously described [9]. Briefly, $95 \mu \mathrm{l}$ of whole blood was collected following decapitation and analyzed within one minute using an i-STAT portable clinical analyzer $\left(\mathrm{EC}^{+}\right.$diagnostic cartridge, Abaxis, Union City, California, USA) to assess sodium $\left(\mathrm{Na}^{+}, \mathrm{mmol} \mathrm{l} \mathrm{l}^{-1}\right)$, potassium $\left(\mathrm{K}^{+}, \mathrm{mmol} \mathrm{l} \mathrm{l}^{-1}\right)$, chloride $\left(\mathrm{Cl}^{-}, \mathrm{mmol} \mathrm{l} \mathrm{l}^{-1}\right), \mathrm{pH}$, dissolved carbon dioxide $\left(\mathrm{pCO}_{2}, \mathrm{mmHg}\right)$, bicarbonate $\left(\mathrm{HCO}_{3}^{-}, \mathrm{mmol}\right.$ $\mathrm{l}^{-1}$ ), base excess (BE, mmol $\mathrm{l}^{-1}$ ), anion gap (AG, mmol $\mathrm{l}^{-1}$ ), blood urea nitrogen (BUN, $\mathrm{mgdL}^{-1}$ ), hematocrit (Hct, \% $\mathrm{PCV})$, and glucose $\left(\mathrm{mgdL}^{-1}\right)$. Remaining blood was centrifuged in microtubes (Stat-Spin, Iris Sample Processing, Westwood, MA) for $90 \mathrm{~s}$, and plasma protein $\left(\mathrm{gdL}^{-1}\right)$ of the serum was measured using a hand-held refractometer (Pulse Instruments, Van Nuys, CA). Temperature-corrected values for $\mathrm{pH}$ and $\mathrm{pCO}_{2}$ were calculated using rectal temperature of the bat at the time of blood collection, and $\mathrm{HCO}_{3}^{-}, \mathrm{AG}$, and $\mathrm{BE}$ were then calculated using these temperaturecorrected values according to the i-STAT manual [53] and specifications of the Clinical Laboratory Standards Institute for Blood Gas and pH Analysis and Related Measurements [54] (see also Additional file 3 for equations).

\section{Isotope analysis}

Capillary tubes containing the blood samples were vacuum distilled [55], and water from the resulting distillate was used to produce $\mathrm{CO}_{2}$ and $\mathrm{H}_{2}$ (methods in [56] for $\mathrm{CO}_{2}$ and [57] for $\mathrm{H}_{2}$ ). The isotope ratios ${ }^{18} \mathrm{O}:{ }^{16} \mathrm{O}$ and ${ }^{2} \mathrm{H}:{ }^{1} \mathrm{H}$ were analyzed using gas source isotope ratio mass spectrometry (Optima, Micromass IRMS and Isochrom $\mu \mathrm{G}$, Manchester, UK). Samples were run alongside three lab standards for each isotope (calibrated to International standards) to correct delta values to $\mathrm{ppm}$. Isotope enrichments were converted to values of daily energy expenditure using a single pool model as recommended for this size of animal [58].

Dilution spaces for oxygen $\left(\mathrm{N}_{0}\right)$ and hydrogen $\left(\mathrm{N}_{\mathrm{d}}\right)$ were calculated by the plateau method (Speakman and Krol, [59]). $\mathrm{CO}_{2}$ production was calculated using equation 7.17 of Speakman [50] and used to estimate DEE according to the Weir equation [59] (see Additional file 2 for details).

\section{Statistical analyses}

Normality of measured parameters was assessed visually using histograms and Q-Q plots for each parameter. Assumptions of normality and homogeneity of variance were satisfied so no transformations were performed. Mean values of measured parameters for infected bats were compared to control bats using independent two-sample $t$-tests. Paired data sets from TBW estimates were compared using paired $t$-tests. All $t$-tests were two-tailed with $\alpha=0.05$, and critical values for significance were adjusted to control the family-wise error rate using the HolmBonferonni method [60] applied separately to each data set: blood chemistry parameters (12 comparisons), DLW measurements (8 comparisons), and torpor profiles (2 comparisons). All statistical analyses were conducted in $R$ [61]. Data in the text are presented as means (SD).

\section{Additional files}

\footnotetext{
Additional file 1: Table of Blood Chemistry Parameters. Comparisons of blood chemistry parameter values for hibernating little brown bats (Myotis lucifugus) experimentally infected with Pseudogymnoascus destructans (Pd) and negative (non-infected) controls to available reference values.

Additional file 2: Doubly Labeled Water. Mean isotope enrichments of administered DLW formulations and background isotope concentrations in bats at the start and end of the experiment. Equations used for calculation of daily energy requirements and fat energy use.
}

Additional file 3: Blood Chemistry Calculations. Equations used to calculate temperature-corrected acid base blood parameters. 


\section{Competing interests}

The authors declare that they have no competing interests.

\section{Authors contributions}

MLV, PMC, JML, and DSB conceived and designed the study. MLV coordinated and conducted the experiment, performed molecular analyses, and analyzed the data. JRS formulated the doubly labeled water (DLW), supervised analyses of DLW samples, and provided expert consult on study design and interpretation of results. MLV, PMC, JML, CUM, and DSB participated in data collection. CUM performed the histopathology examinations for disease confirmation. MLV wrote the manuscript, all co-authors provided input, and DSB edited the manuscript. All authors read and approved the manuscript.

\section{Acknowledgments}

This project was financially supported by the US Geological Survey through a cooperative agreement with the University of Wisconsin Madison. We are indebted to Dave and Jennifer Redell and Paul White from the Wisconsin Department of Natural Resources for collecting the animals used to complete this study and for assisting with data collection. We thank Melissa Behr for assistance with necropsies and NWHC Animal Care Staff for their help with set-up and maintenance of animals. We thank Lobke Vaanholt and Catherine Hambly (University of Aberdeen, Scotland) for their expertise and coordination in the analyses of the DLW blood samples. Funds were used for direct project costs only. Use of trade, product, or firm names is for descriptive purposes only and does not imply endorsement by the US Government.

\section{Author details}

${ }^{1}$ Department of Pathobiological Sciences, School of Veterinary Medicine, University of Wisconsin-Madison, 2015 Linden Dr., Madison, Wisconsin, USA. ${ }^{2}$ US Geological Survey National Wildlife Health Center, 6006 Schroeder Rd., Madison, Wisconsin, USA. ${ }^{3}$ Institute of Biological and Environmental Sciences, University of Aberdeen, Aberdeen, Scotland, UK. ${ }^{4}$ US Geological Survey Fort Collins Science Center, 2150 Centre Ave. Building C, Fort Collins, Colorado, USA. ${ }^{5}$ US Geological Survey National Center, Environmental Health, 12201 Sunrise Valley Dr., Reston, Virginia, USA.

Received: 4 June 2014 Accepted: 18 November 2014

Published online: 09 December 2014

\section{References}

1. Blehert DS, Hicks AC, Behr MJ, Meteyer CU, Berlowski-Zier BM, Buckles EL, Coleman ЛH, Darling SR, Gargas A, Niver R, Okoniewski JC, Rudd RJ, Stone WB: Bat white-nose syndrome: an emerging fungal pathogen? Science 2009, 323:227.

2. Frick WF, Pollock JF, Hicks AC, Langwig K, Reynolds DS, Turner GG, Butchkoski $\mathrm{CM}$, Kunz TH: An emerging disease causes regional population collapse of a common North American bat species. Science 2010, 329:679 682.

3. Turner GG, Reeder DM, Coleman JC: A five-year assessment of mortality and geographic spread of white-nose syndrome in North American bats and a look to the future. Bat Res News 2011, 52:13 27.

4. Gargas A, Trest MT, Christensen M, Volk TJ, Blehert DS: Geomyces destructans sp. nov. asssociated with bat white-nose syndrome. Mycotaxon 2009, 108:147 154.

5. Minnis AM, Lindner DL: Phylogenetic evaluation of Geomyces and allies reveals no close relatives of Pseudogymnoascus destructans, comb. nov., in bat hibernacula of eastern North America. Fungal Biol 2013, 117:638 649.

6. Lorch JM, Muller LK, Russell RE, O Connor M, Lindner DL, Blehert DS: Distribution and environmental persistence of the causative agent of white-nose syndrome, Geomyces destructans, in bat hibernacula of the eastern United States. Appl Environ Microbiol 2012, 79:1293 2839.

7. Cryan PM, Meteyer CU, Boyles JG, Blehert DS: Wing pathology of white-nose syndrome in bats suggests life-threatening disruption of physiology. BMC Biol 2010, 8:135.

8. Willis CKR, Menzies AK, Boyles JG, Wojciechowski MS: Evaporative water loss is a plausible explanation for mortality of bats from white-nose syndrome. Integr Comp Biol 2011, 51:364 373.

9. Cryan PM, Meteyer CU, Blehert DS, Lorch JM, Reeder DM, Turner GG, Webb J, Behr M, Verant ML, Russell RE, Castle KT: Electrolyte depletion in white-nose syndrome bats. J Wildlife Dis 2013, 49:398 402

10. Warnecke L, Turner JM, Bollinger TK, Misra V, Cryan PM, Blehert DS, Wibbelt G, Willis CKR: Pathophysiology of white-nose syndrome in bats: a mechanistic model linking wing damage to mortality. Biol Lett 2013, 9:20130177.
11. Reeder DM, Frank CL, Turner GG, Meteyer CU, Kurta A, Britzke ER, Vodzak ME, Darling SR, Stihler CW, Hicks AC, Jacob R, Grieneisen LE, Brownlee SA, Muller LK, Blehert DS: Frequent arousal from hibernation linked to severity of infection and mortality in bats with white-nose syndrome. Plos One 2012, 7:e38920.

12. Warnecke L, Turner JM, Bollinger TK, Lorch JM, Misra V, Cryan PM, Wibbelt G, Blehert DS, Willis CKR: Inoculation of bats with European Geomyces destructans supports the novel pathogen hypothesis for the origin of white-nose syndrome. Proc Natl Acad Sci U S A 2012, 109:6999 7003.

13. Kayser C: The Physiology of Natural Hibernation. Oxford: Pergamon Press; 1961.

14. Thomas DW, Dorais M, Bergeron JM: Winter energy budgets and cost of arousals for hibernating little brown bats, Myotis lucifugus. J Mammal 1990, 71:475 479.

15. Geiser F: Metabolic rate and body temperature reduction during hibernation and daily torpor. Annu Rev Physiol 2004, 66:239 274.

16. Butler PJ, Green JA, Boyd IL, Speakman JR: Measuring metabolic rate in the field: the pros and cons of the doubly labelled water and heart rate methods. Funct Ecol 2004, 18:168 183.

17. Lifson N, Gordon GB, McClintock R: Measurement of total carbon dioxide production by means of $\mathrm{D}_{2} \mathrm{O}^{18}$. J Appl Physiol 1955, 7:704 710 .

18. Speakman JR, Visser GH, Ward SE, Krl E: The Isotope Dilution Method for the Evaluation of Body Composition. In Body Composition Analysis of Animals. Edited by Speakman JR. Cambridge: Cambridge University Press; 2001:56 98.

19. Kurta A, Bell GP, Nagy KA, Kunz TH: Energetics of pregnancy and lactation in free-ranging little brown bats (Myotis lucifugus). Physiol Zool 1989, 62:804 818

20. Kurta A, Kunz TH, Nagy KA: Energetics and water flux of free-ranging big brown bats (Eptesicus fuscus) during pregnancy and lactation. J Mammal 1990, 71:59 65

21. Meteyer CU, Buckles EL, Blehert DS, Hicks AC, Green DE, Shearn-Bochsler V, Thomas NJ, Gargas A, Behr MJ: Histopathologic criteria to confirm white-nose syndrome in bats. J Vet Diagn Invest 2009, 21:411 414.

22. Malan A, Arens $H$, Waechter A: Pulmonary respiration and acid base state in hibernating marmots and hamsters. Respir Physiol 1973, 17:45 61.

23. Szewczak JM: Matching gas exchange in the bat from flight to torpor. Am Zool 1997, 37:92 100.

24. Malan A, Mioskowski E, Calgari C: Time-course of blood acid base state during arousal from hibernation in the European hamster. J Comp Physiol B 1988, 158:495 500.

25. Snapp BD, Heller HC: Suppression of metabolism during hibernation in ground squirrels (Citellus lateralis). Physiol Zool 1981, 54:297 307.

26. Bickler PE: $\mathrm{CO}_{2}$ balance of a heterothermic rodent: comparison of sleep, torpor, and awake states. Am J Physiol 1984, 246:49 55.

27. Szewczak JM, Jackson DC: Acid base state and intermittent breathing in the torpid bat, Eptesicus fuscus. Respir Physiol 1992, 88:205 215.

28. Thomas DW, Cloutier D, Gagne D: Arrhythmic breathing, apnea and non-steady state oxygen uptake in hibernating little brown bats (Myotis lucifugus). J Exp Biol 1990, 149:395 406.

29. Thomas DW, Cloutier D: Evaporative water-loss by hibernating little brown bats, Myotis lucifugus. Physiol Zool 1992, 65:443 456.

30. Munoz-Garcia A, Ben-Hamo M, Pinshow B, Williams JB, Korine C: The relationship between cutaneous water loss and thermoregulatory state in Kuhl s pipistrelle Pipistrellus kuhlii, a Vespertillionid bat. Physiol Biochem Zool 2012, 85:516 525.

31. Speakman JR, Racey PA: Hibernal ecology of the Pipistrelle bat - energyexpenditure, water requirements and mass-loss, implications for survival and the function of winter emergence flights. J Anim Ecol 1989, 58:797 813.

32. Ben-Hamo M, Munoz-Garcia A, Williams JB, Korine C, Pinshow B: Waking to drink: rates of evaporative water loss determine arousal frequency in hibernating bats. J Exp Biol 2013, 216:573 577.

33. Meteyer CU, Valent M, Kashmer J, Buckles EL, Lorch JM, Blehert DS, Lollar A, Berndt D, Wheeler E, White CL, Ballmann AE: Recovery of little brown bats (Myotis lucifugus) from natural infection with Geomyces destructans, white-nose syndrome. J Wildlife Dis 2011, 47:618 626.

34. Riedesel ML: Blood Physiology. In Biology of Bats. Volume 3. Edited by Wimsatt W. New York: Academic Press; 1977:651.

35. Cryan PM, Wolf BO: Sex differences in the thermoregulation and evaporative water loss of a heterothermic bat, Lasiurus cinereus, during its spring migration. J Exp Biol 2003, 206:3381 3390.

36. Riedesel ML, Folk GE Jr: Serum electrolyte levels in hibernating mammals. Am Nat 1958, 92:307 312. 
37. Riedesel ML: Serum magnesium levels in mammalian hibernators. Trans Kans Acad Sci 1957, 60:99 141.

38. Kallen FC: Plasma and blood volumes in the little brown bat. Am J Physiol 1960, 198:999 1005.

39. Blood FR, Dodgen CL: Energy sources in the bat. Am J Physio/ 1956, 187:151 154.

40. Humphries MM, Thomas DW, Speakman JR: Climate-mediated energetic constraints on the distribution of hibernating mammals. Nature 2002, 418:313 316.

41. Malan A: Respiration and Acid Base State in Hibernation. In Hibernation and Torpor in Mammals and Birds. Edited by Lyman CP, Willis JS, Malan A, Wang LCH. New York: Academic Press; 1982:237 282.

42. Hochachka PW, Guppy M: Metabolic arrest and the control of biological time. Cambridge, MA: Harvard University Press; 1987

43. Malan $\mathrm{A}: \mathrm{pH}$ and hypometabolism in mammalian hibernation. Can J Zool 1988, 66:95 98.

44. Schaefer KE, Wunnenberg W: Threshold temperatures for shivering in acute and chronic hypercapnia. J Appl Physiol 1976, 41:67 70.

45. Studier EM, Fresquez AA: Carbon dioxide retention: a mechanism of ammonia tolerance in mammals. Ecology 1969, 50:492 494.

46. Herreid CF 2nd, Bretz WL, Schmidt-Nielsen K: Cutaneous gas exchange in bats. Am J Physiol 1968, 215:506 508.

47. Makanya AN, Mortola JP: The structural design of the bat wing web and its possible role in gas exchange. J Anat 2007, 211:687 697.

48. Muller LK, Lorch JM, Lindner DL, O Connor M, Gargas A, Blehert DS: Bat white-nose syndrome: a real-time TaqMan polymerase chain reaction test targeting the intergenic spacer region of Geomyces destructans. Mycologia 2012, 105:253 259

49. Lorch JM, Meteyer CU, Behr MJ, Boyles JG, Cryan PM, Hicks AC, Ballmann AE, Coleman JTH, Redell D, Reeder DM, Blehert DS: Experimental infection of bats with Geomyces destructans causes white-nose syndrome. Nature 2011, 480:376 378.

50. Kunz TH, Nagy KA: Methods of Energy Budget Analysis. In Ecological and Behavior Methods for the Study of Bats. Edited by Kunz TH. Washington, D.C: Smithsonian Institution Press; 1988:277 302.

51. Speakman JR: Doubly Labelled Water- Theory and Practice. London: Chapman and Hall; 1997.

52. Speakman JR, Racey PA: The equilibrium concentration of O-18 in body-water: implications for the accuracy of the doubly-labeled water technique and a potential new method of measuring RQ in free-living animals. J Theor Biol 1987, 127:79 95.

53. Abbott Point of Care Inc: iStat Instruction Manual. Abbott Park, IL: Abbott Point of Care Inc; 2008

54. Clinical Laboratory Standards Institute: Blood gas and pH Analysis and Related Measurements: Approved Guideline - Second Edition. Wayne, PA: CLSI; 2009.

55. Nagy KA: The Doubly Labeled Water ${ }^{3} \mathrm{HH}^{18} \mathrm{O}$ Method: A Guide to its use. Los Angeles: University of California; 1983.

56. Speakman JR, Nagy KA, Masman D, Mook WG, Poppitt SD, Strathearn GE, Racey PA: Interlaboratory comparison of different analytical techniques for the determination of oxygen-18 abundance. Anal Chem 1990, 62:703 708 .

57. Speakman JR, Krol E: Comparison of different approaches for the calculation of energy expenditure using doubly labeled water in a small mammal. Physiol Biochem Zool 2005, 78:650 667.

58. Speakman JR: How should we calculate $\mathrm{CO}_{2}$ production in doubly labelled water studies of animals? Funct Ecol 1993, 7:746 750.

59. Weir JB: New methods for calculating metabolic rate with special reference to protein metabolism. J Physiol 1949, 109:1 9.

60. Holm S: A simple sequentially rejective multiple test procedure. Scand J Stat 1979, 6:65 70.

61. R: A Language and Environment for Statistical Computing. [http://www. R-project.org]

doi:10.1186/s12899-014-0010-4

Cite this article as: Verant et al:: White-nose syndrome initiates a cascade of physiologic disturbances in the hibernating bat host. BMC Physiology 2014 14:10.

\section{Submit your next manuscript to BioMed Central and take full advantage of:}

هConvenient online submission

$\otimes$ Thorough peer review

$\otimes$ No space constraints or color $₫$ gure charges

$\otimes I m m e d i a t e$ publication on acceptance

\Inclusion in PubMed, CAS, Scopus and Google Scholar

$\otimes$ Research which is freely available for redistribution

Submit your manuscript at www.biomedcentral.com/submit 